\title{
DO FINANCIAL INVESTORS DESTABILIZE THE OIL PRICE?
}

by Marco J. Lombardi and Ine Van Robays 


\title{
WORKING PAPER SERIES
}

NO I346 I JUNE 20II

\section{DO FINANCIAL \\ INVESTORS DESTABILIZE \\ THE OIL PRICE? '}

\author{
by Marco J. Lombardi ${ }^{2}$ \\ and Ine Van Robays ${ }^{3}$
}

NOTE: This Working Paper should not be reported as representing the views of the European Central Bank (ECB).

The views expressed are those of the authors and do not necessarily reflect those of the ECB.

This paper can be downloaded without charge from http://www.ecb.europa.eu or from the Social Science Research Network electronic library at http://ssrn.com/abstract_id = 1847503.

I This paper was initiated when the second author was with the European Central Bank. Without implicating, we would like to thank Bahattin Büyüksahin, Gert Peersman, Jaap Bos, Julio Carrillo, Lutz Kilian, Punnoose Jacob, Sandra Eickmeier and an anonymous referee

for their useful comments and suggestions.

2 Directorate General Economics, European Central Bank, Kaiserstrasse 29, D-603II Frankfurt am Mai, Germany; e-mail: marco.lombardi@ecb.europa.e 3 Department of Financial Economics, Ghent University, Woodrow Wilsonplein 5D, B-9000 Gent, 
(C) European Central Bank, 2011

\section{Address}

Kaiserstrasse 29

60311 Frankfurt am Main, Germany

Postal address

Postfach 160319

60066 Frankfurt am Main, Germany

Telephone

+496913440

Internet

http://www.ecb.europa.eu

Fax

+496913446000

All rights reserved.

Any reproduction, publication and reprint in the form of a different publication, whether printed or produced electronically, in whole or in part, is permitted only with the explicit written authorisation of the ECB or the authors.

Information on all of the papers published in the ECB Working Paper Series can be found on the ECB's website, http://www. ecb.europa.eu/pub/scientific/wps/date/ html/index.en.html

ISSN 1725-2806 (online) 


\section{CONTENTS}

Abstract

Non technical summary

1 Introduction

2 Understanding financial activity in oil futures markets

2.1 The oil futures market

2.2 The link between spot and futures prices

3 Model specification and identification

3.1 A structural VAR model

3.2 Identification of different types of oil shocks I7

4 Empirical results

4.1 Effects of different types of oil shocks 20

4.2 Relevance of different types of oil shocks 22

4.3 Explaining recent oil price fluctuations 23

4.4 Robustness of the results 25

5 Conclusions 27

References 29

Appendix 32

Figures $\quad 34$ 


\begin{abstract}
In this paper, we assess whether and to what extent financial activity in the oil futures markets has contributed to destabilize oil prices in recent years. We define a destabilizing financial shock as a shift in oil prices that is not related to current and expected fundamentals, and thereby distorts efficient pricing in the oil market. Using a structural VAR model identified with sign restrictions, we disentangle this non-fundamental financial shock from fundamental shocks to oil supply and demand to determine their relative importance. We find that financial investors in the futures market can destabilize oil spot prices, although only in the short run. Moreover, financial activity appears to have exacerbated the volatility in the oil market over the past decade, particularly in 2007-2008. However, shocks to oil demand and supply remain the main drivers of oil price swings.
\end{abstract}

Keywords: Oil price, Speculation, Structural VAR, Sign restrictions.

JEL Classification : C32, Q41, Q31. 


\section{Non-technical summary}

The massive oil price fluctuations observed in the last few years have stimulated the debate on the role of financial activity in the determination of oil prices. The oil futures market has indeed become increasingly liquid, and the activity of agents that do not deal with physical oil, the so-called 'non-commercials', has greatly increased. This led some to hypothesize that inflows of financial investors in the futures market may have pushed oil prices above the level warranted by fundamental forces of supply and demand, whereas others argue that the impact of financial activity on the oil spot market is negligible or non-existent beyond the very short term.

In this paper, we evaluate the importance of financial activity in determining the spot price of oil relative to the role of oil market fundamentals, by relying on a sign-restricted structural VAR model. We disentangle stabilizing from destabilizing financial activity in the oil futures market based on a set of simple theoretical equations that link the oil spot market to the futures market through a no-arbitrage condition. A destabilizing financial shock enters this framework by creating a deviation from the no-arbitrage condition, thereby distorting efficient price formation by driving oil futures prices away from the levels justified by oil market fundamentals. On the other hand, stabilising financial activity is defined as driven by changes in oil supply and demand-side fundamentals. Elaborating upon the work of Peersman and Van Robays (2009a,b) and Kilian and Murphy (2010) by explicitly including the futures market in a sign-restricted VAR, we identify four different types of oil shocks: an oil supply shock, an oil demand shock driven by economic activity, an oil-specific demand shock which captures changes in oil demand other than those caused by economic activity, and a destabilizing financial shock.

Our results suggest that financial activity in the futures market can significantly affect oil prices in the spot market, although only in the short run. The destabilizing financial shock only explains about 10 percent of the total variability in oil prices, and shocks to fundamentals are clearly more important over our sample. Indeed, looking at specific points in time, the gradual run-up in oil prices between 2002 and the summer of 2008 was mainly driven by a series of stronger-than-expected oil demand shocks on the back of booming economic activity, in combination with an increasingly tight oil supply from mid 2004 on. Strong demand-side growth together with stagnating supply were also the main driving factors behind the surge in oil prices in 2007-mid 2008, and the drop in oil prices 
in the second half of 2008 can be mainly explained by a substantial fallback in economic activity following the financial crisis and the associated decline in global oil demand. Since the beginning of 2009, rising oil demand on the back of a recovering global economy also drove most of the recovery in oil prices.

However, we find that financial investors did cause oil prices to significantly diverge from the level justified by oil supply and demand at specific points in time. In general, inefficient financial activity in the futures market pushed oil prices about 15 percent above the level justified by (current and expected) oil fundamentals over the period 2000-mid 2008, when the volume of crude oil derivatives traded on NYMEX quintupled. Particularly in 2007-2008, destabilizing financial shocks aggravated the volatility present in the oil market and caused oil prices to respectively over- and undershoot their fundamental values by significant amounts, although oil fundamentals clearly remain more important. 


\section{Introduction}

The massive oil price fluctuations observed in the last few years led many commentators to reexamine the functioning of the price-setting mechanism in the oil market (Khan 2009, Kaufmann and Ullman 2009, Miller and Ratti 2009 and Lombardi and Mannucci 2011). ${ }^{1}$ The increasing financialization of the oil futures markets was blamed by some as the main driver of the escalation of oil prices, in addition to the more conventional explanations of surging demand and tight oil supply. It is indeed true that the oil futures market has become increasingly liquid, and the activity of agents that do not deal with physical oil, the so-called 'non-commercials', has greatly increased. Furthermore, passive index funds, whose goal is to provide investors with long-only exposure to oil, have witnessed substantial inflows in recent years (CFTC 2008). This led some to hypothesize that such inflows in the futures market may have pushed oil prices above the level warranted by fundamental forces of supply and demand.

Using a sign-restricted structural VAR model, this paper evaluates the importance of financial activity in determining the spot price of oil relative to the role of oil market fundamentals. Our identification scheme is based on a set of simple theoretical equations that link the oil spot market to the futures market through a no-arbitrage condition. A destabilizing financial shock enters this framework by creating a deviation from the no-arbitrage condition, thereby distorting efficient price formation by driving oil futures prices away from the levels justified by oil market fundamentals. This way, we separate stabilizing from destabilizing financial activity in the oil futures market.

Our results suggest that financial activity in the futures market can significantly destabilize oil prices in the spot market, although only in the short run. In contrast, fundamental shocks to oil supply and oil demand cause oil prices to shift permanently. Over different forecast horizons, the destabilizing financial shock only explains about 10 percent of the total variability in oil prices, as shocks to fundamentals account for about 90 percent of the forecast error variance decomposition over our sample. Moreover, we find that financial investors did cause oil prices to diverge significantly from the level justified by oil supply and demand at specific points in time over the past decade, particularly in 2007-2009.

\footnotetext{
${ }^{1}$ After having surged with increasing momentum to an unprecedented level of USD 120 per barrel in the summer of 2008, oil prices fell abruptly to reach USD 45 per barrel at the end of 2008 in the wake of the financial crisis and the subsequent global economic downturn. Oil prices started rebounding in the second quarter of 2009 and experienced a strong upturn rising since then.
} 
However, innovations to fundamentals still account for most part of recent oil price fluctuations. More specifically, the gradual run-up in oil prices between 2002 and the summer of 2008 was mainly driven by a series of stronger-than-expected oil demand shocks on the back of booming economic activity, in combination with an increasingly tight oil supply from mid 2004 on. Strong demand-side growth together with stagnating supply are also the main driving factors behind the surge in oil prices in 2007- mid 2008, consistent with the results in the literature (e.g. Hamilton 2009, Kilian 2009 and related papers). Nevertheless, financial activity caused oil prices to significantly overshoot their fundamental level in the first half of 2008. This is also true for the second half of 2008, in which oil prices dropped considerably in the wake of the financial crisis and the subsequent global economic downturn. Again, most part of the decline in oil prices was driven by a strong unexpected drop in global oil demand, but financial activity caused oil prices to decline far below the level explained by the reduction in oil demand. The contributions of the destabilizing financial shock to the oil price over time can be associated with large flows in and out of passive index funds linked to oil. Finally, we find that rising oil demand on the back of a recovering global economy drove most of the recent recovery in oil prices since the beginning of 2009 .

This paper relates to different strands of the oil literature. First, several studies have analyzed the effect of speculation on the oil spot price, mostly using data on trader's positions in the futures market (IMF 2006, Haigh et al. 2007 and Büyüksahin et al. 2008). However, the distinction made between speculative activity (i.e. non-commercial trading) and non-speculative activity (i.e. commercial trading or hedging) may be arbitrary in some cases, and the publicly available data on speculative trading activity is not completely representative of all sorts of financial activity in these futures markets. ${ }^{2}$ For example, the above-mentioned index funds only enter on the long side of the crude oil futures market to hedge. Although the activity of index funds is typically not regarded as speculation, as they follow a passive investment strategy, the index funds can distort price formation by causing oil prices to deviate from levels justified by fundamentals by creating additional demand in the futures market. This type of financial activity is not accounted for when using non-commercial trading data to assess the impact of speculative trading on the oil price. Moreover, studies that want to evaluate the role of the index funds directly using trader's position data, also have to rely on rough approximations. ${ }^{3}$ For this reason, we will

\footnotetext{
${ }^{2}$ See Sanders et al. (2004) for a more detailed explanation.

${ }^{3}$ Irwin and Sanders (2010), for example, proxy index fund positions by swap dealer positions in the
} 
assess the impact of financial activity on oil spot prices without relying on trader position data. Moreover, we will only evaluate the impact of financial activity that effectively distorts price formation in the oil market, and that can create deviations in the oil price from the level justified by oil demand and supply-side fundamentals.

A second strand of related literature examines the effect of changing oil demand and supply-side fundamentals on the oil price. In addition to the non-fundamental shock, we identify shocks to oil market supply and demand-side fundamentals. Most of the policy and academic literature still ascribes the recent oil price fluctuations to changes in fundamentals. The gradual rise over the period 2003-2008 is usually explained by increasing oil demand, and also the oil price run-up of 2007-2008 is mainly attributed to strong oil demand confronting stagnating global oil production (Hamilton 2009, Kilian 2009 and related papers). Baumeister and Peersman (2008, 2010) observe that the price elasticities of oil demand and supply have become much smaller over time, leading to increased oil price sensitivity to similar changes in fundamentals. Anzuini, Lombardi and Pagano (2010) highlight that expansionary monetary policy may have fueled oil price increases, but also report that it appears to exert its impact through expectations of higher inflation and growth, rather than on the flow of global liquidity into oil futures markets. By identifying both fundamental and non-fundamental oil shocks, we are able to balance the importance of fundamentals against that of inefficient financial activity. Elaborating upon the work of Peersman and Van Robays (2009a,b) and Kilian and Murphy (2010) by explicitly including the futures market in a sign-restricted VAR, we identify four different types of oil shocks: an oil supply shock, an oil demand shock driven by economic activity, an oil-specific demand shock which captures changes in oil demand other than those caused by economic activity, and a destabilizing financial shock.

The paper is organized as follows: in the next section we cast a formal definition of destabilizing financial activity in a simple theoretical framework. We describe the VAR model specification and the identification strategy in Section 3, and discuss the empirical results in Section 4; Section 5 concludes.

futures market to evaluate the impact of index funds on commodity futures markets. Although this is a fair approximation for agricultural commodity markets, this is not the case for energy markets as swap dealers operating in energy markets only conduct a limited amount of long-only index swap transactions (CFTC 2008). 


\section{Understanding financial activity in oil futures markets}

In the oil futures markets, we can separate desirable 'stabilizing' from undesirable 'destabilizing' financial activity. The former relates to the fact that agents intervening in the oil futures market bring their information sets and expectations on future fundamentals into the pricing mechanism, thereby contributing to the price-discovery mechanism, in addition to making the markets more liquid. However, if agents place their bets disregarding the expectations on fundamentals the price-setting mechanism can be distorted. Only this latter type of inefficient financial activity matters to policy makers and regulators, and we will regard this non-fundamental financial shock in the futures markets as related to speculative activity. In this section, we shed some light on the concept of destabilizing financial trading by looking at the functioning of oil futures markets and the link between the futures and the spot market for crude oil.

\subsection{The oil futures market}

In the case of commodities, futures markets exist as a means of transferring risks of price fluctuations. Typically, two main type of traders are identified to be active in the oil futures market, i.e. commercial and non-commercial traders. Agents who deal with physical oil, often labeled as commercials, may wish to hedge against price fluctuations by fixing in advance the price they will have to pay or receive for a delivery in the future. Oil producers will therefore have the opportunity to secure their income today by selling futures contracts, and oil consumers will buy futures contracts in order to pin down their future costs. Yet, agents not dealing with physical oil also participate in the market, making the oil market more liquid. These non-commercials intervene in oil futures market because they want to achieve exposure to oil price risk, either on the upside or downside, to make a profit.

Typically, speculative behavior in the oil market is attributed to the financial activity of traders that actively enter the futures market and buy or sell according to (expected) fundamentals. The CFTC ascribes speculative activity to the non-commercial traders that make profits based on their expectations of the future oil supply-demand balance. Without relying on trader position data, Kilian and Murphy (2010) also define speculation in the oil market as related to oil fundamentals, i.e. a speculation shock in their framework is "any oil demand shock that reflects shifts in expectations about future oil production or 
future real activity (p.9)".

In reality, however, movements in futures prices do not always reflect efficient pricing of the expected oil supply-demand balance. For example, agents may intervene in the futures market not because they have expectations on the future dynamics of oil fundamentals, but rather because they want to allocate part of their portfolio to oil. There is indeed a good motivation to do so, as oil futures are commonly thought to be a hedge against inflation, and to be negatively correlated with stock market indices. Commodity-related index funds were created to allow investors to easily achieve exposure to commodity price risk, and accordingly they only enter on the long side of the crude oil futures market, independent on whether future oil fundamentals are strong or weak. Although they follow a passive trading strategy, these financial funds may distort price formation by causing oil prices to deviate from levels justified by current or expected fundamentals. The magnitude of the inflows into such index funds is precisely one of the reasons why many observers attributed for the recent volatile behavior of oil prices to speculation. This type of speculation, or more generally financial activity, is neither captured by looking at non-commercial positions, as index fund traders are regarded as commercial traders, nor is it specifically captured in the framework employed by Kilian and Murphy (2010). ${ }^{4}$

To wrap up, we define destabilizing financial trading in oil markets based on identifying two types of financial activity in the oil futures market. The first type occurs on the back of changing expectations about oil market fundamentals. This does not distort the efficient functioning of the oil market, but rather enhances the oil price formation mechanism by bringing in new information on expected fundamentals. Conversely, the second type of financial activity occurs independently of (current and expected) oil supply and demand fundamentals, thereby distorting efficient pricing in the futures and spot market by causing prices to deviate from their levels justified by fundamentals. We will define this type of trading as destabilizing financial activity. In the next subsection, we will exploit the theoretical link between the oil spot and futures market to better characterize these two types of financial activity.

\footnotetext{
${ }^{4}$ The scheme used by Kilian and Murphy (2010) to identify the speculation shock could be consistent with the way we identify the inefficient financial shock later on, under the condition that inefficient financial trading contemporaneously affects oil prices and inventories in the spot market. However, our aim is to focus on non-fundamental futures market shocks and remain agnostic about the impact of destabilizing financial activity on oil prices and inventory holdings in the spot market, as the exact transmission to the oil spot market is not explicitly known.
} 


\subsection{The link between spot and futures prices}

Of course, financial activity in the futures market only matters if changes in futures prices can affect oil prices in the spot market. This linkage between the spot and the futures market for oil is commonly represented by a no-arbitrage condition (Pindyck 1993, Alquist and Kilian 2010). We will rely on this condition to give a theoretical characterization of the two types of activity in futures markets, fundamental versus non-fundamental, which will also prove useful for the identification of these shocks later on.

Let us consider an investor who holds $P_{t}$ units of the numeraire at time $t$. He can either invest in a risk-free bond with yield $r_{t}$, or buy oil, store it and sell it on the futures market for delivery in $t+\tau$. Buying oil, however, also brings an additional benefit, in that the investor has access to a commodity that he can exploit, if needed. We will label this benefit as the convenience yield, and denote it as $\Psi_{t, t+\tau}$ (Pindyck 1993). ${ }^{5}$ By the no-arbitrage principle, the two investment strategies should bear the same return. If we denote the spot price as $P_{t}$ and the future price $F_{t, t+\tau}$, we have:

$$
P_{t}\left(1+r_{t}\right)^{\tau}=F_{t, t+\tau}+\Psi_{t, t+\tau}
$$

Taking logarithms, Equation (1) becomes:

$$
p_{t}+\tau r_{t}=f_{t, t+\tau}+\psi_{t, t+\tau}
$$

So, if markets are efficient and arbitrage opportunities are exploited instantaneously, Equation (2) would hold. If the convenience yield, net of storage costs, is positive, this will imply that spot prices are higher than futures, which explains why the futures curve in commodities markets is often negatively sloped (backwardation). However, if storage costs are higher than the convenience yield, it would be possible to observe a positive-sloped futures curve (contango). Rewriting Equation (2) gives an expression of the futures price in terms of the spot oil price, the convenience yield and the risk-free rate:

$$
f_{t, t+\tau}=p_{t}-\psi_{t, t+\tau}+\tau r_{t}
$$

Pindyck (1994) postulates a relationship between the convenience yield on the one hand, and the oil spot price, oil inventories and expected fundamentals on the other:

$$
\psi_{t, t+\tau}=G\left[p_{t}, I_{t}, E\left(D_{t, t+\tau}\right)\right]
$$

\footnotetext{
${ }^{5}$ Here, we abstract from the fact that oil has to be stored and this operation has a price, hence the convenience yield will be expressed net of storage costs.
} 
where $I_{t}$ is the level of inventories, $E\left(D_{t, t+\tau}\right)$ is the expected demand over period $t$ to $t+\tau$ and $G$ denotes a generic function. ${ }^{6} G$ is increasing in $p_{t}$, since higher prices imply a higher convenience in holding inventories, decreasing in $I_{t}$ since at times of low inventories the marginal yield of an additional unit is higher, and increasing in $E\left(D_{t, t+\tau}\right)$ since higher expected demand makes holding inventories more convenient, as future market tightness is expected. Note that also expected future supply tightness will increase the convenience yield of holding inventories. Hence, we can assume that the term $E\left(D_{t, t+\tau}\right)$ captures the overall effect of expected fundamentals on the convenience yield.

Substituting Equation (4) into Equation (3) gives the following:

$$
f_{t, t+\tau}=p_{t}-G\left[p_{t}, I_{t}, E\left(D_{t, t+\tau}\right)\right]+\tau r_{t}
$$

In the efficient, no-arbitrage case, the futures price depends positively on the current spot price, negatively on expected oil fundamentals and positively on the risk-free rate.

If agents in the economy are homogeneous, they will all have access to the same information set and process the flow of news homogeneously, so that Equation (5) will always hold. More specifically, all other things equal, futures prices will be moved by the flow of news that changes expectations on future demand and supply, such as an expected depreciation of the US dollar or other fundamental shocks that can affect the future oil supply-demand balance. Based on this news on (expected) fundamentals, agents will place their bets in both the futures and spot market and thereby change the futures and spot price according to the no-arbitrage condition, so that it will always hold.

However, and without the need to depart from rationality, players in commodity markets are indeed not homogeneous. Let us concentrate on the oil futures market, in which players can participate for other reasons than buying or selling futures based on their expectations on oil fundamentals. When an index fund receives an inflow by an investor, e.g. by someone who wants to invest in commodities to hedge against inflation risks, it will then buy oil futures irrespective of its expectations on the oil supply and demand balance. Conversely, if an outflow from an index fund materializes, e.g. because an investor needs to reduce his leverage, the fund will sell oil futures, again irrespective of fundamentals. ${ }^{7}$

\footnotetext{
${ }^{6}$ There is no need to specify the functional form of the function $G$ in more detail, as the identification of the different types of oil shocks will only depend on the sign of the relationship between the convenience yield and its deteminants.

${ }^{7}$ More generally, this reasoning will apply to any agent that places his bets irrespective of fundamentals, e.g. uninformed noise traders or technical analysts who try to jump on price trends.
} 
Such interventions will also affect the futures price set in the market, thereby generating a deviation from the fundamental no-arbitrage relationship, so that the observed future price becomes:

$$
f_{t, t+\tau}^{\circ}=f_{t, t+\tau}+\epsilon_{t}^{f}
$$

with $f_{t, t+\tau}$ the futures price that would prevail if the no-arbitrage condition was always satisfied and the futures price is solely determined by fundamental factors, i.e. the one found in Equation (5). The term $\epsilon_{t}^{f}$, which we assume to be weakly stationary, represents the deviation of the observed future price from its no-arbitrage value. This shock $\epsilon_{t}^{f}$, which we will label the destabilizing financial shock, creates a perturbation in the futures market in the sense that demand for futures contracts driven by this sort of speculation moves the observed futures price away from its fundamentally justified level. ${ }^{8}$

How can an inefficient perturbation to oil futures prices transmit to oil spot prices? In the no-arbitrage framework, if expected changes in oil fundamentals move the futures price, the spot price will be affected via the inventory channel. This is exactly how Kilian and Murphy (2010) identify their speculation shock, i.e. as an inventory demand shock in the spot market. We, however, want to assess the effect of financial activity in the futures market that is not related to fundamentals, and enters our framework as a deviation of the no-arbitrage equation. ${ }^{9}$ The exact transmission of this inefficient financial shock is thus less well-known. A first possibility is that arbitrageurs in the spot market will recognize the perturbation as not linked to expected fundamentals, and hence accumulate (or dump) inventories to exploit the arbitrage opportunity. In addition to this, other players in the physical market may instead interpret the price signal as genuinely related to changing expectations on fundamentals, and hence adjust their supply and demand

\footnotetext{
${ }^{8}$ In order for the deviation to persist and hence be observable, we must hypothesize that there are frictions (e.g. physical constraints) that prevent agents to immediately arbitrage away the misalignment. In general, we remark that the presence of frictions cannot be interpreted as a source of misalignment in the pricing equations (i.e. they do not constitue per se a shock), but rather they impact on the absorption of misalignments (i.e. the speed at which shocks die out).

${ }^{9}$ As mentioned before, the speculation shock identified in Kilian and Murphy (2010) could be consistent with the way we identify the inefficient financial shock if we impose that the transmission to the spot market goes through the inventory channel and necessarily affects the spot price and oil production within the same month that the shock hits. However, our aim is to model fundamental versus non-fundamental financial activity in the futures market to assess to which extent inefficient financial activity transmits to oil spot prices, whereas Kilian and Murphy (2010) assume complete pass-through from the futures to the spot market, and therefore do not include the futures price in their model.
} 
decisions. Moreover, it could also be that it takes some time for the agents in the spot market to recognize and interpret this deviation. A priori, it is not exactly known how a change in the futures price following a destabilizing speculation shock is transmitted to the spot market, and therefore we remain agnostic on this. More specifically, we will decide to leave the response of the spot price and oil inventories over to the data in the empirical part. What we do know is that the destabilizing financial shock has an impact on the spread. Let us substitute Equation (5) into Equation (6) to get:

$$
f_{t, t+\tau}^{\circ}=p_{t}-G\left[p_{t}, I_{t}, E\left(D_{t, t+\tau}\right)\right]+\tau r_{t}+\epsilon_{t}^{f}
$$

According to Equation (7), the observed futures price is a function of the spot price, current and expected changes related to fundamentals and the destabilizing financial shock. So, futures are allowed to vary based current or expected changes to oil supply and demand as well as for destabilizing speculation in the futures market. Hence, Equation (7) captures the two types of activity in oil futures markets defined above in Section 2.1.

To see this more clearly, let us rewrite Equation (7) in terms of the observed futuresspot spread:

$$
s_{t, t+\tau}^{\circ}=f_{t, t+\tau}^{\circ}-p_{t}=\underbrace{-G\left[p_{t}, I_{t}, E\left(D_{t, t+\tau}\right)\right]+\tau r_{t}}_{(1)}+\underbrace{\epsilon_{t}^{f}}_{(2)}
$$

where $s_{t, t+\tau}^{\circ}$ is the observed futures-spot spread between $t$ and $t+\tau$. This equation expresses the spread in terms of a fundamental component (1) and a component (2) that takes into account destabilizing financial activity and the chance that prices may be misaligned with respect to the level warranted by (current and expected) fundamentals. Assuming that storage costs are constant, changes in (expected) fundamentals will negatively affect the spread, whereas the destabilizing financial shocks will have a positive impact, since it increases observed futures prices via Equation (6). The fact that the futures-spot spread reacts differently to the two different kinds of activity in the futures market (i.e. trading based on fundamentals and destabilizing financial activity) will prove useful to uniquely identify these shocks and their importance later on. ${ }^{10}$ For example, suppose that the ex-

\footnotetext{
${ }^{10}$ Note that although the risk free rate is part of the fundamental component, it positively affects the spread and therefore could be wrongly identified as part of the destabilizing financial shock. However, as long as interest rates are at low levels, and we look at short maturities, this should not matter much. Indeed, based on our results, the correlation between the structural financial shock and the risk-free interest rate, proxied by the Federal Funds rate, is only 0.01 and insignificant, which indicates that we are not confiusing inefficient financial shocks for shocks to the interest rate.
} 
pected oil supply-demand balance becomes tighter because of unrest in the Middle-East, then both the futures and the spot price will increase to satisfy the no-arbitrage condition, but as the convenience yield will rise as well, the increase in the spot price should be more pronounced than the rise in the futures prices so that the futures-spot spread declines. On the other hand, when an inflow in an index fund pushes the futures price upwards, the spot price might increase as well, but not by more than the futures price. If expected fundamentals do not change after the destabilizing financial shock but inventory holdings possibly increase, then the convenience yield will decline. In turn, this decrease in the convenience yield will counteract a possible decline in the spread as spot prices increase cfr. Equation (8).

\section{Model specification and identification}

Although the importance of financial activity in determining oil price fluctuations is still strongly debated, it is common knowledge that, at least in the long run, oil fluctuations are mainly driven by changes in oil supply and demand. In order to get a comprehensive view on the determinants of oil prices, we will identify oil price movements that are driven by conventional oil supply and demand shocks in addition to those related to destabilizing financial activity.

\subsection{A structural VAR model}

To evaluate the role of the different types of shocks in determining the oil price, we employ a structural vector autoregression (SVAR) framework that has the following general representation:

$$
X_{t}=c+A(L) X_{t-1}+B \varepsilon_{t}
$$

The vector of endogenous variables $X_{t}$ captures the global dynamics in the oil spot and futures market by including world oil production $\left(Q_{o i l}\right)$, the price of crude oil expressed in US dollars $\left(P_{o i l}\right)$, a measure of world economic activity $\left(Y_{w}\right)$, the futures price of oil $\left(F_{\text {oil }}\right)$ and oil inventories $\left(I_{t}\right)$. To avoid redundant variables, we do not include the spread $\left(s_{t, t+\tau}\right)$ in the model, but generate the response as the difference between the estimated level response of the futures and spot price of oil. $c$ is a vector of constants, $A(L)$ is a matrix polynomial in the lag operator $L$ and $B$ is the contemporaneous impact matrix 
of the vector of orthogonalized error terms $\varepsilon_{t}$. The oil price is the nominal Brent crude oil spot price and the futures-spot spread is based on the associated 3-month futures contracts. Although the Brent futures market is somewhat thinner than the WTI market, we use the Brent oil price as a global benchmark for the reason that WTI oil is mainly used in the US, whereas the Brent is used to specify two-thirds of crude oil exchanged world-wide on the ICE futures exchange. ${ }^{11}$ We proxy global economic activity by the OECD measure of global industrial production, which covers the OECD countries and the six major non-OECD economies, including e.g. China and India. Following Kilian and Murphy (2010), we proxy global crude oil inventories as total US crude oil inventories, scaled by the ratio of OECD petroleum stocks over US petroleum stocks. The VAR model is estimated using monthly data over the sample period 1991:01-2010:02, and we include 12 lags of the endogenous variables. ${ }^{12}$ All the variables are transformed to monthly growth rates by taking the first difference of the natural logarithm, and the variables are corrected for seasonality. In general, the results are quite robust to different specifications of the variables and the SVAR model, see the discussion in Section 4.4 .

\subsection{Identification of different types of oil shocks}

The recent literature has clearly shown that different factors can drive oil price movements, and that the economic consequences crucially depend on the underlying source of the oil price change (Kilian 2009 and related papers, Peersman and Van Robays 2009a,b). We identify four different types of shocks: an oil supply shock, an oil demand shock driven by economic activity, an oil-specific demand shock (i.e. the fundamental shocks), and a destabilizing financial shock (i.e. the non-fundamental shock). We do this by relying on the following set of sign restrictions: ${ }^{13}$

\footnotetext{
${ }^{11}$ Moreover, the Brent price is gaining momentum as a global benchmark as recent movements in the WTI crude oil price were mainly reflecting regional surplus inventory capacity in Cushing, Oklahoma, instead of pricing in the increased market tightness following unrest in the Middle-East.

${ }^{12}$ Although lag selection criteria propose to only include 2 or 3 lags, we decide to include one year of lags; this is required to allow for enough dynamics in the macroeconomic variables following an oil shock, see Hamilton and Hererra (2004). The start of the sample period is determined by the availabilty of futures price data.

${ }^{13}$ The sign restrictions are shown for oil shocks that increase the oil futures price. A more detailed explanation on the use of sign restrictions can be found in the appendix.
} 


\begin{tabular}{l|cccccc}
\hline \hline STRUCTURAL SHOCKS & $Q_{\text {oil }}$ & $P_{\text {oil }}$ & $Y_{w}$ & $I_{t}$ & $F_{\text {oil }}$ & $s_{t, t+\tau}$ \\
\hline $\begin{array}{l}\text { Non-fundamental shocks } \\
\text { Destabilizing financial activity }\end{array}$ & & & & & & \\
\hline Fundamental shocks & & & & & $\geq 0$ & $\geq 0$ \\
Oil supply & $\leq 0$ & $\geq 0$ & $\leq 0$ & $\geq 0$ & $\leq 0$ \\
Oil demand driven by economic activity & $\geq 0$ & $\geq 0$ & $\geq 0$ & $\geq 0$ & $\leq 0$ \\
Oil -specific demand & $\geq 0$ & $\geq 0$ & $\leq 0$ & $\geq 0$ & $\leq 0$ \\
\hline \hline
\end{tabular}

First, we disentangle the fundamental oil shocks from the non-fundamental financial shocks. We do this by imposing opposite signs on the response of the spread, based on Equation (8). The fundamental shocks which increase oil prices have a negative effect on the futures-spot spread, whereas destabilizing financial activity increases the spread after increasing the futures price of oil. ${ }^{14}$ Hence, we define the destabilizing financial shock as a shock to the futures markets that raises the oil futures price and increases the futures-spot spread. This could for example reflect the trading behavior of index funds that enter the oil futures market to provide a hedge against inflation, irrespective of oil market fundamentals. Note that we do not restrict any of the responses in the oil spot market following a destabilizing financial shock, as the effect on the oil spot market and the exact transmission mechanism is a priori unknown.

Second, we further disentangle the fundamental shocks into shocks caused by shifting oil demand and oil supply. Following Baumeister and Peersman (2010) and Peersman and Van Robays (2009a,b), we disentangle the fundamental oil supply and oil demand shocks by relying on a set of signs derived from a simple supply-demand scheme of the oil market. Shocks on the supply side of the oil market shift the oil supply curve and therefore move oil prices and oil production in opposite directions. Shocks on the demand side of the oil market shift the oil demand curve and therefore cause oil prices and oil production to move in the same direction. More specifically, an unfavorable oil supply shock is an exogenous shift of the oil supply curve to the left which lowers oil production and increases oil prices, whilst world industrial production does not increase. Exogenous

\footnotetext{
${ }^{14}$ In order to disentangle the fundamental versus the non-fundamental shocks, we only look at the change in the spread, i.e. the difference between the change in the level of the futures price and the change in the level of the oil spot price. The restriction imposed on the spread does thus not imply that the market should be in contango or backwardation.
} 
oil production disruptions caused by geopolitical tensions in the Middle-East are a natural example. Consistent with the no-arbitrage condition, oil futures prices will increase after this shock, but less than proportionally, so that the futures-spot spread declines. This is because the convenience yield will also be higher after the increase in oil spot prices driven by the oil supply shock.

In contrast, a favorable oil demand shock driven by global economic activity and the accompanying rise in overall commodity demand will increase both oil production and oil prices as this shock is represented by an upward shift of the oil demand curve. By definition, such shocks are associated with an increase in global economic activity. A natural example of this type of shock is the surge in oil demand on the back of strong economic growth in emerging economies such as China and India. Again, to satisfy the no-arbitrage condition, the futures price will increase and the futures-spot spread will decline.

Finally, an unfavorable oil-specific demand shock is a demand shock for oil which is not driven by stronger economic growth. This shock also raises oil prices and oil production, but is associated with a negative, or rather non-positive, effect on economic activity. As this oil price increase is also driven by fundamentals, the futures price will increase and the spread will decline according to the no-arbitrage condition. Two examples of this are an oil substitution shock and an expected oil fundamentals shock. Rising demand for oil caused by increased substitution of coal for oil will drive up the price of oil, increase oil production and will not be favorable for economic activity because of the higher oil price. On the other hand, an expected fundamental shock, e.g. tighter expected oil supply or demand, will raise oil demand due to an increased demand for oil inventories. This will increase both the oil price and production, and will not stimulate economic activity as oil prices are higher. However, we do not restrict the response of inventories following the oil-specific shock to capture a broader set of oil-specific demand shocks beyond these expected fundamental shocks.

Kilian and Murphy (2010), in contrast, separately identify an expected oil fundamental shock in their SVAR model identified with sign restrictions. Their expected fundamental shock is characterized as an oil inventory demand shock, which increases oil inventories, the oil price and production, and decreases world economic activity. As mentioned before, they interpret this expected fundamentals shock as a speculation shock. We, however, focus on financial activity that is actually detrimental for the functioning of the oil futures 
market, i.e. all the trading activity in the futures market that can not be related to (expected) fundamentals. In our framework, we consider the expected oil fundamental shock of Kilian and Murphy (2010) as one that still reflects efficient market functioning, and is part of the more general fundamental oil-specific demand shock.

As we only identify four oil shocks using a five-variable SVAR model, a residual shock will capture all the structural shocks not accounted for. This residual shock has no direct economic interpretation, and based on the results described in the next section, its importance in explaining oil spot and futures prices appears to be small.

\section{Empirical results}

\subsection{Effects of different types of oil shocks}

Figure 1 shows the estimated $68 \%$ confidence bands of the impulse response functions to the different types of oil shocks. The estimated responses are shown in levels up to 60 months after the shock, and the oil shocks have been normalized to contemporaneously increase the oil price by $10 \%$. We find it convenient to also show the estimated median response as a possible summary measure, even though the median responses are prone to some criticism and should therefore be interpreted with caution (see Fry and Pagan 2010 for more details). ${ }^{15}$

Similar to Kilian (2009) and Peersman and Van Robays (2009a,b), we find that the effects of an oil price increase crucially depend on the underlying source of the increase. First, the exogenous oil supply shock causes oil production to decline and oil prices to increase permanently. A temporarily lower level of inventories partially counterbalances the fall in oil supply, although not significantly, and the oil supply shock significantly reduces the level of economic activity. The dynamics of the response of the oil futures price is very similar to those of the oil price in the spot market, although the futures price increases by less so that the spread declines. This decline is only temporary, indicating that following the oil supply shock, the slope of the oil futures curve does not significantly change in the somewhat longer term. Second, the permanent oil price increase caused by a shock in oil demand driven by economic activity is associated with an increase in oil

\footnotetext{
${ }^{15}$ The results based on the $68 \%$ range are instead not subject to this critique as they describe a range of possible outcomes.
} 
production and a positive effect on industrial production, which is not surprising given that this shock is identified as an aggregate demand shock that boosts demand for oil. Oil inventories tend to lower temporarily to partially address the increased demand for oil, although this decline is not significant. Again, the response of the oil futures price is very similar to the one of the spot price, and the spread temporarily declines. Third, the oilspecific demand shock also causes oil spot prices to be permanently higher. The increased demand for oil raises oil production and has a negative effect on the level of economic activity. Oil inventories do not respond significantly, which is probably due to the fact that this shock captures a wide variety of oil-specific demand shocks with diverging effects on inventories. ${ }^{16}$ The spread again only declines in the short-run.

Interestingly, not only the fundamental shocks, but also the destabilizing financial shock affects oil spot prices significantly. As expected, this effect on the oil spot price is only short-lived, in contrast to the oil price responses following the fundamental shocks which are permanent. The pass-through of the destabilizing financial shock in futures prices to the spot market price for oil is incomplete, and the futures-spot spread increases permanently. ${ }^{17}$ We do not find a significant reaction of oil production or oil inventories, nor do we find that destabilizing financial activity has real economic effects. ${ }^{18}$ The insignificant response of oil inventories is interesting given the current discussion in the literature on the relationship between inventories and speculation. Much of the anecdotal evidence against a role of speculation is that during the past few years, there was no noticeable increase in inventories (e.g. Irwin and Sanders 2010). However, using a simple theoretical model, Hamilton (2009) shows that speculation can affect spot oil prices without triggering a significant rise in inventories as long as the price elasticity of oil demand is small. We find that financial activity is indeed not necessarily associated with a significant change in

\footnotetext{
${ }^{16}$ For example, an expected fundamental shock is likely to increase inventories as agents in the physical market want to anticipate the future oil price increase, and a substitution shock is more likely to decrease oil inventories because of the unexpected increase in oil demand.

${ }^{17}$ This implies that it is necessary to include futures market variables in the model when assessing the role of speculation, since relying on a full pass-through of futures price shocks to oil spot prices via the no-arbitrage condition is empirically not correct. Therefore, the assumption made by Kilian and Murphy (2010) to not explicitly model the oil futures market when assessing the role of speculation, and only use spot oil market variables in their SVAR, is restrictive.

${ }^{18}$ The insignificant response of production can not be conclusive on the validity of the Hotelling principle, which argues that oil producers have the tendency to keep oil production in the ground as futures prices are higher than spot prices. We would expect this effect to play only when the market is in contango, i.e. spot prices are lower than futures prices.
} 
inventories but can still affect the spot price of oil, if speculation is defined as inefficient trading in the futures market. ${ }^{19}$

\subsection{Relevance of different types of oil shocks}

The impulse response analysis shows that destabilizing financial activity in the futures markets can matter as it significantly affects spot oil prices. The forecast error variance decomposition will shed some light on the overall importance of destabilizing financial trading for explaining the variability of oil spot prices over our sample, relative to the fundamental shocks. Figure 2 shows this forecast error decomposition of the oil spot price and the oil futures price. The variance decompositions are obtained using the posterior median draw. ${ }^{20}$

The left-hand side of Figure 2 displays the forecast error variance decomposition of the oil spot price. It is clear that the largest part of oil price fluctuations over our sample are explained by shocks to fundamentals. Over the different forecast horizons, more than 90 percent of the forecast error is attributable to fundamental shocks in oil demand and supply. Not surprisingly, oil demand shocks driven by economic activity account for most part of this contribution, explaining more than 40 percent of the forecast error variance. Shocks to oil supply account for about 30 percent of the forecast error in the short run, which however declines in the longer run. Clearly, this implies that the importance of non-fundamental financial shocks is rather limited. Over the different forecast horizons, the destabilizing financial shocks accounts for about 10 percent of the forecast error decomposition on average. Although this contribution is very limited relative to those of the fundamental shocks, inefficient trading can account for a non-negligible part of oil price variability.

The right-hand side of Figure 2 shows the forecast error decomposition of the futures price. Destabilizing financial activity plays a significantly larger role in explaining futures price movements, contributing more than 20 percent to the forecast errors at very short

\footnotetext{
${ }^{19}$ In their SVAR, Kilian and Murphy (2010) limit the response of inventories following their speculation shock by restricting the magnitude of the price elasticity of oil demand, in order to be consistent with the theoretical results of Hamilton's (2009) model on speculation. This is rather counterintuitive since they actually define a speculation shock as an oil inventory shock in the spot market. By defining speculation differently, i.e. an inefficiency shock in the futures market, we do not need to impose this restriction.

${ }^{20}$ We refer to Section 4.4 for robustness checks on alternative choices of this specific draw. The forecast error decompositions of the other variables in the SVAR model are available on request.
} 
horizons. This contribution declines somewhat at longer horizons, reaching 16 percent in the long run. Indeed, futures price variability is also for most part explained by shocks to (expected) fundamentals, and by oil demand shocks driven by economic activity in particular. The smaller contribution of the destabilizing financial shock in the spot market indicates that not all inefficient trading in the oil futures markets is passed on to the oil spot market, which is consistent with the incomplete pass-through of the destabilizing financial shock to oil spot prices found in the impulse response analysis. Finally, note that the contribution of the non-identified residual shock is very small in the short run, implying that the four shocks identified in our framework capture almost the entire shortrun forecast error variability of oil spot and futures prices over our sample.

\subsection{Explaining recent oil price fluctuations}

Although inefficient financial trading only explains a limited part of the overall oil price variability over our sample, speculative activity could still be important for understanding the increased volatility in oil prices over the last decade, and during 2007-2008 in particular. To assess these contributions at each point in time, it is useful to look at the historical decomposition together with the nominal oil spot price in USD per barrel given in Figure 3. The historical decompositions are obtained from the posterior median draw. ${ }^{21}$ The historical contributions are accumulated and expressed in percentage deviations from the baseline unconditional forecast excluding the structural shocks. A declining contribution is associated with a negative shock that reduces oil prices, and vice versa. For the reason that the more recent period is of main interest, and the financialization of the commodity markets gained momentum from 2000 on, we concentrate on the evolution of the oil price over the period 2000:01 - 2010:02. ${ }^{22}$

In 2001, after having fluctuated around USD 25 per barrel in 2000, oil prices declined owing to a series of negative global oil demand shocks due to a slowdown in economic activity. This decrease in oil demand can be related to the global decline in GDP growth in 2001 in the context of the early millennium slowdown. Since early 2002, however, oil prices surged with increasing momentum to reach about USD 120 per barrel in June 2008, before plummeting to around USD 45 per barrel in the aftermath of the financial crisis

\footnotetext{
${ }^{21}$ We refer to Section 4.4 for the robustness of the results of the historical decomposition to this choice.

${ }^{22}$ The contributions are normalised to zero in 2000:01. The historical decomposition of the oil price and the other variables in the model over the full sample period are available upon request.
} 
which hit the global economy in the summer of 2008. Figure 3 clearly shows that the continued increase in oil prices from 2002 till mid 2008 is mainly caused by positive oil demand shocks driven by growing economic activity, which pushed oil prices more than 30 percent higher than the baseline projection over this period. It is well known that the emerging economies became increasingly important as major oil importers since the early 2000s. Accordingly, strong economic growth in the emerging economies which boosted demand for commodities in general can explain most part of the surge in oil prices over this period. ${ }^{23}$ This rising demand came against the background of increasing tightness in oil supply when global oil production began to stagnate in 2004, mainly due to non-OPEC countries. Therefore, negative oil supply shocks also contributed significantly to the surge in oil prices, causing them to be about 12 percent higher than the baseline projection between 2003 and mid-2008. Oil-specific demand shocks lifted oil prices higher by more than 20 percent, which makes the total contribution of oil demand shocks in general clearly dominant. Although the contribution of the oil-specific demand shock is compatible with a variety of interpretations, one possibility is increased demand for oil driven by a tighter expected oil supply-demand balance in the future.

There is some consensus that steeply rising oil demand together with tighter oil supply are the driving factors behind the gradual increase in oil prices since 2003 (e.g. ECB 2010). On the factors behind the strong fluctuations in the oil spot price between 2007 and the beginning of 2010, there is less clarity. Hamilton (2009) finds that it is possible to explain the main part of the oil price run-up in 2007-2008 based on fundamentals, i.e. strong demand confronting stagnating supply. Using a simple theoretical model, however, he argues that speculation could have played a role as well, although fundamentals are likely to be more important. By testing this within an empirical framework, we find similar results for destabilizing financial activity. Figure 3 clearly shows that the considerable rise in oil prices was due to a series of oil demand shocks driven by economic activity, together with increasingly tighter oil supply which aggravated the upward move in oil prices. This can be linked to the observation that the capacity utilization rate at which OPEC was producing increased, leaving less room to absorb unexpected oil demand shocks. Interestingly, we find that also financial trading plays an important role in explaining the steep oil price run up in 2007-2008, and pushed oil prices about 12 percent higher than

\footnotetext{
${ }^{23}$ Also Baumeister and Peersman (2008), Hamilton (2009), Kilian (2009) and related papers find that shocks to oil demand are mainly responsible for the continued increase in oil prices since 2003.
} 
the level justified by fundamentals over the period 2007:08 - 2008:06. ${ }^{24}$ This could indeed be associated with the relevant inflows into passive exchange-traded funds linked to oil.

In the second half of 2008 , oil prices dropped by 62 percent from peak to trough on the back of a slowdown in economic activity and the onset of the financial crisis. Figure 3 indicates that this period was characterized by a substantial fall in oil demand on the back of slowing economic activity, whereas global oil production remained tight. Again, inefficient financial trading contributed significantly to the fall in oil prices, leading to an undershooting of more than 20 percent with respect to the baseline projection over the period 2008:07 - 2008:12. This came against the background of massive outflows from passive index funds due to the onset of the global financial crisis which led many agents to unwind their positions in risky assets to reduce their leverage. In the beginning of 2009, oil demand started to increase again on the back of a recovering global economy, which explains most part of the rise in oil prices since then.

In a nutshell, we do find that destabilizing financial shocks played a role in explaining oil price fluctuations over the last decade. Over the period 2000-2008, in which the volume of crude oil derivatives traded on NYMEX quintupled, inefficient activity in the futures market pushed oil prices about 15 percent above the level justified by (current and expected) oil fundamentals. Particularly in 2007-2008, destabilizing financial shocks aggravated the volatility present in the oil market. However, it is clear that shocks to oil demand and supply remain the most important determinants of oil price movements.

\subsection{Robustness of the results}

In this section, we assess whether the main conclusions of the paper still hold for reasonable changes in the specification of the SVAR model. More specifically, we will evaluate whether it is still the case that the destabilizing financial shock (i) affects the oil spot price significantly but has no real economic effects and (ii) only plays a limited role in explaining the variability in oil futures and spot prices over our sample because oil fundamentals are far more important. Moreover, we test whether the inefficient financial trading shock (iii) increased the volatility of oil prices over time, and caused oil spot prices to significantly overshoot and undershoot their fundamental level in 2007-2009, although (iv) most of the evolutions of the oil price over the last decade are explained by rising oil demand together

\footnotetext{
${ }^{24}$ In a different econometric framework, similar results are also found by Lombardi and Mannucci (2011).
} 
with increasingly tight supply.

First, the conclusions are robust to using real oil prices, different maturities for the futures contracts (i.e. 2, 6 and 12 months-ahead futures), the global economic activity measure based on cargo freight rates proposed by Kilian (2009), and reasonable variation in the number of lags for the endogenous variables in the VAR given our sample period (9 and 18 lags). Specifically, the contribution of the destabilizing financial shock over the period 2000:01 - 2008:06 ranges between 14 and 23 percent for the different specifications tested compared to 15 percent for our benchmark specification. ${ }^{25}$

Second, a well-know critique on the sign restriction methodology concerns the way in which the results are summarized. For the reason that the sign restrictions methodology does not generate a unique model, the impulse response functions are often based on the median draw. However, Fry and Pagan (2010) demonstrate that the impulse response functions could come from different models, which implies that the shocks implicit in the impulse response functions are not necessarily orthogonal. To test for this, we generate the variance decomposition and the historical decomposition of the benchmark VAR model based on the 'closest-to-median' draw proposed by Fry and Pagan (2010), which preserves the orthogonality between the shocks. ${ }^{26}$ The results are shown in Panel A of Figure 4 and 5. Although the overall importance of the destabilizing financial shock reduces somewhat when using the closest-to-median draw, the main conclusions of the paper are unchanged.

However, the unique draw proposed by Fry and Pagan (2010) could still lead to the choice of a specific model which generates results that are qualitatively very different from those of the other models satisfying the sign restrictions. Therefore, we narrow the number of admissible models down by imposing additional restrictions on the bounds of the shortrun price elasticity of oil supply and demand, as suggested by Kilian and Murphy (2009). We restrict the impact price elasticity of oil supply to be lower than 0.025 and the impact price elasticity of oil demand to lie between -0.8 and 0, similar to Kilian and Murphy (2010). The results for the variance decomposition and the historical decomposition are

\footnotetext{
${ }^{25}$ The contribution of the destabilizing financial activity shock is $16.8,16.9,14.3,14.5,17.2,13.9$ and 22.6 for the specification with real oil prices, 2-, 6- and 12 month ahead futures, the economic activity indicator proposed by Kilian (2009) and using 9 and 18 lags for the endogenous variables respectively. More detailed results are available upon request from the authors.

${ }^{26}$ We only show the results for the variance decomposition and the historical decomposition as the impulse response functions describe a range of possible outcomes which is not in violation of the Fry and Pagan critique.
} 
shown in Panel B of Figure 4 and 5. Although the variance decomposition indicates a modest change in the relative importance among the fundamental shocks, in favor of the oil-specific demand shock, the historical decomposition shows that recent evolutions in the oil price are still explained by rising oil demand and tightening oil supply. Moreover, the destabilizing financial shock remains a non-negligible factor in the explanation of the increased volatility of oil prices over time, and in 2007-2009 in particular.

\section{Conclusions}

In this paper, we analyzed the role of financial trading in determining the price of oil over the past two decades, with a special focus on the 2007-2009 period. As the activity of financial investors in oil futures markets can at the same time enhance and distort the price formation mechanism in the oil market, we separated two types of activity in the oil futures market. The first type of trading occurs on the back of fundamentals, and therefore makes price formation in the oil markets more efficient. We identified three types of oil fundamental shocks, i.e. an oil supply shock, an oil-demand shock driven by economic activity and an oil-specific demand shock. Each shock has different effects on the oil spot market variables and global economic activity. The second type of activity in the futures market occurs independently of oil fundamentals and distorts the price signals in the oil market. We label this non-fundamental shock as a destabilizing financial shock, and define it as a deviation from the no-arbitrage condition which captures trading that is not consistent with movements in oil supply and demand. In our view, defining speculation in this way enables us to study the role of financial activity in the oil market more comprehensively than the literature has done so far. Moreover, as only financial activity that distorts efficient price formation is not desirable, we argue that also this type of trading is more relevant for policy makers and regulators. We disentangle the different types of oil shocks using a structural VAR model of the global oil spot and futures market identified with sign restrictions. Several interesting conclusions emerge from our analysis.

First, we find that financial activity in the futures market can significantly affect the spot oil price. This implies that financial trading matters, although its effect on spot oil prices is only short-lived. Destabilizing financial shocks do not affect oil production or inventories, and fail to have any significant real effects. The pass-through of the financial shock in the futures markets to the oil spot market appears to be incomplete as the 
futures-spot price permanently increases. Second, destabilizing financial shocks do not explain much of the variability in oil prices, as shocks to oil fundamentals account for more than 90 percent of the forecast error variance decomposition over the different horizons. Third, looking at specific points in time over the past decade, we find that the largest part of the gradual run-up in oil prices over the 2002-2008 period is driven by unexpected increases in oil demand in the wake of a growing global economy, amid increasingly tight oil supply. Stronger oil demand and tight oil supply also explain most part of the surge in oil prices between 2007 and mid-2008, and the drop in oil prices in the second half of 2008 is also mainly on the back of a strong fall in oil demand driven by the global economic downturn that followed the financial crisis. As global economic activity gradually recovered from early 2009 on, oil prices increased again due to a recovering global demand for oil. However, financial trading also mattered over the past decade, leading oil prices to deviate considerably from the level justified by fundamentals. In particular in 2007-2008, destabilizing financial activity caused oil prices to respectively over- and undershoot their fundamental values by significant amounts.

Although we propose a way to identify destabilizing activity in the futures market, and disentangle this financial shock from innovations in oil supply and demand, capturing all relevant financial activity in the futures markets remains a difficult task. An interesting avenue for future research is therefore to implement financial trading in the futures market in a fully-fledged theoretical model, in order to better understand how speculation, and more generally financial activity, can impact on the price of oil. 


\section{References}

[1] Anzuini, A., M.J.Lombardi and P.Pagano (2010): The impact of monetary policy shocks on commodity prices, ECB Working Paper 1232.

[2] Alquist, R. and L. Kilian (2010): What do we learn from the price of crude oil futures?, Journal of Applied Econometrics, forthcoming.

[3] Baumeister, C. and G. Peersman (2008): Time-varying effects of oil supply shocks on the US economy, Ghent University Working Paper 2008/515.

[4] Baumeister, C. and G. Peersman (2010): Sources of the volatility puzzle in the crude oil market, Ghent University Working Paper 2010/634.

[5] Büyüksahin, B., Haigh, M.S., Harris, J.H., Overdahl, J.A. and M.A. Robe (2008): Fundamentals, trader activity and derivative pricing, EFA 2009 Bergen Meetings Paper.

[6] Commodity Futures Trading Commission (2008): Interim report on crude oil, July 2008.

[7] ECB (2010): Oil prices - Their determinants and impact on euro area inflation and the macroeconomy, Monthly Bulletin, August: 75-92.

[8] Fry, R. and A. Pagan (2010): Sign restrictions in structural vector autoregressions: a critical review, NCER Working Paper Series $5 \%$.

[9] Haigh, M.S., Hranaiova, J. and J.A. Overdahl (2007): Price volatility, liquidity provision, and the role of hedge funds in energy futures markets, Journal of Alternative Investments: Spring 200\%.

[10] Hamilton, J.D. (2009): Causes and consequences of the oil shock of 2007-08, NBER Working Papers 15002.

[11] Hamilton, J.D. and A.M. Hererra (2004): Comment: Oil shocks and aggregate macroeconomic behavior: The role of monetary policy, Journal of Money, Credit and Banking 36(2): 265-286.

[12] International Energy Agency (2009): Medium-term oil market report, June 2009. 
[13] International Monetary Fund (2006): The boom in nonfuel commodity prices: can it last?, World Economic Outlook, Chapter 5: September 2006.

[14] Irwin, S. H. and D. R. Sanders (2010): The impact of index and swap funds on commodity futures markets: preliminary results, OECD Food, Agriculture and Fisheries Working Papers, No. 2

[15] Kaufmann R.K. and B.Ullman (2009): Oil prices, speculation, and fundamentals: Interpreting causal relations among spot and futures prices, Energy Economics 31: 550-558.

[16] Khan, M.S. (2009): The 2008 oil price "bubble", Peterson Institute for International Economics Policy Brief PB09-19.

[17] Kilian, L. (2009): Not All Oil Price Shocks are alike: disentangling demand and supply shocks in the crude oil market, American Economic Review 99: 1053-1069.

[18] Kilian, L. and D. Murphy (2009): Why are agonistic sign restrictions not enough: Understanding the dynamics of oil market VAR models, Journal of the European Economic Association, forthcoming.

[19] Kilian, L. and D. Murphy (2010): The role of inventories and speculative trading in the global market for oil, mimeo, University of Michigan.

[20] Lombardi, M.J. and D. Mannucci (2011): Measuring oil price over- and undershooting, mimeo, European Central Bank.

[21] Miller, J.I. and R.A. Ratti (2009): Crude oil and stock markets: Stability, instability, and bubbles, Energy Economics 31: 559-568.

[22] Peersman, G. (2005): What caused the early millennium slowdown? Evidence based on vector autoregressions, Journal of Applied Econometrics 20: 185-20\%.

[23] Peersman, G. and I. Van Robays (2009a): Oil and the euro area economy, Economic Policy 24(60): 603-651.

[24] Peersman, G. and I. Van Robays (2009b): Cross-country differences in the effects of oil shocks, Ghent University Working Paper 2009/629. 
[25] Pindyck, R.S. (1993): The present value model of rational commodity pricing, Economic Journal 103: 511-530.

[26] Pindyck, R.S. (1994): Inventories and the short-run dynamics of commodity prices, RAND Journal of Economics 25: 141-159.

[27] Sanders, D.R., K. Boris and M. Manfredo (2004): Hedgers, funds, and small speculators in the energy futures markets: an analysis of the CFTC's Commitments of Traders reports, Energy Economics 26: 425-445. 


\section{Appendix}

\section{Sign restrictions in practice}

As mentioned in the text, we rely on the following structural VAR model to identify the impact of the different types of oil shocks:

$$
X_{t}=c+A(L) X_{t-1}+B \varepsilon_{t}
$$

with $X_{t}$ the vector of five endogenous variables (oil price, oil production, world industrial production, oil futures price and oil inventories), $c$ a vector of constants, $A(L)$ a matrix polynomial in the lag operator $L$ and $B$ the contemporaneous impact matrix of the vector of orthogonalized error terms $\varepsilon_{t}$. In this paper, we want to estimate the effects of four different types of oil shocks, i.e. oil supply shock, oil demand shock driven by economic activity, oil-specific demand shock and the destabilizing financial shock. However, it is not possible to estimate the contemporaneous impact matrix $B$ and therefore identify the structural innovations in $\varepsilon_{t}$ without further assumptions. In particular, since the structural shocks are mutually orthogonal, the variance-covariance matrix of a reduced form estimation of the VAR is $\Omega=B^{\prime} B$. Given $\Omega$, there are an infinite number of possible $B$. In the case of sign restrictions, a set of possible $B$ are considered conditional on fulfilling a number of sign conditions. Peersman (2005) shows how to generate all possible decompositions. To uniquely disentangle the four types of oil shocks, we implement the sign restrictions which are explained in Section 3.2. We impose the sign restrictions to hold for the first 12 months after the shocks, except for the response of the spread which is only imposed contemporaneously.

As in Peersman (2005), we use a Bayesian approach for estimation and inference. Our prior and posterior distributions of the reduced form VAR belong to the NormalWishart family. To draw the "candidate truths" from the posterior, we take a joint draw from the unrestricted Normal-Wishart posterior for the VAR parameters as well as a random possible block lower triangular decomposition $B$ of the variance-covariance matrix, which allows us to construct impulse response functions. If the impulse response functions from a particular draw satisfy the imposed sign conditions, the draw is kept. Otherwise, the draw is rejected by giving it a zero prior weight. We require each draw to satisfy the restrictions of all four shocks simultaneously. Note that the restrictions 
following the destabilizing financial shock are only imposed on the futures price and the futures-spot spread, the responses of the spot oil market variables are fully determined by the data. A total of 1000 "successful" draws from the posterior are then used to show the 68 percent probability range of possible impulse responses to the shocks in Figure 1, together with the median response. In general, we need 188179 draws to find 1000 successful identifications, which indicates that the data is relatively in favor of the model that generates the sign restrictions. When imposing additional sign restrictions on the bounds of the price elasticity of oil supply and demand, in line with Kilian and Murphy (2010), we need more than 355000 rotations for finding one successful draw. 
FUNDAMENTAL
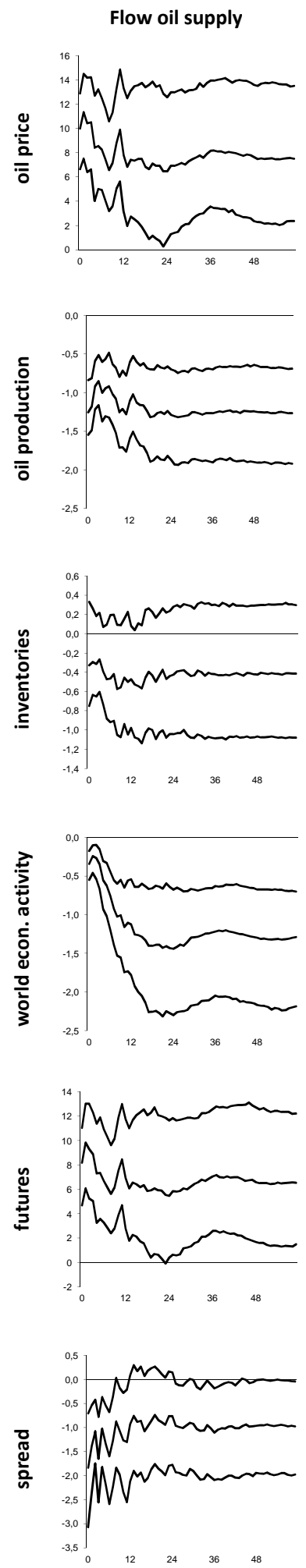

Flow oil demand shock
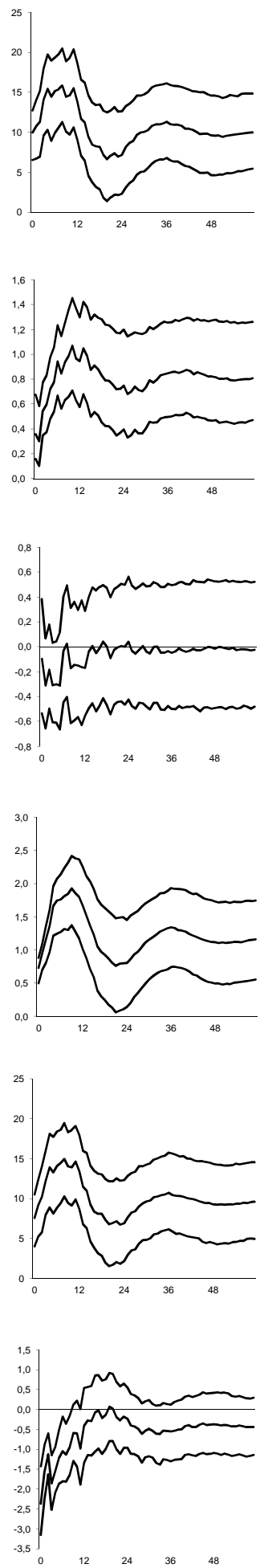

NON-FUNDAMENTAL

Destab. fin. activity shock
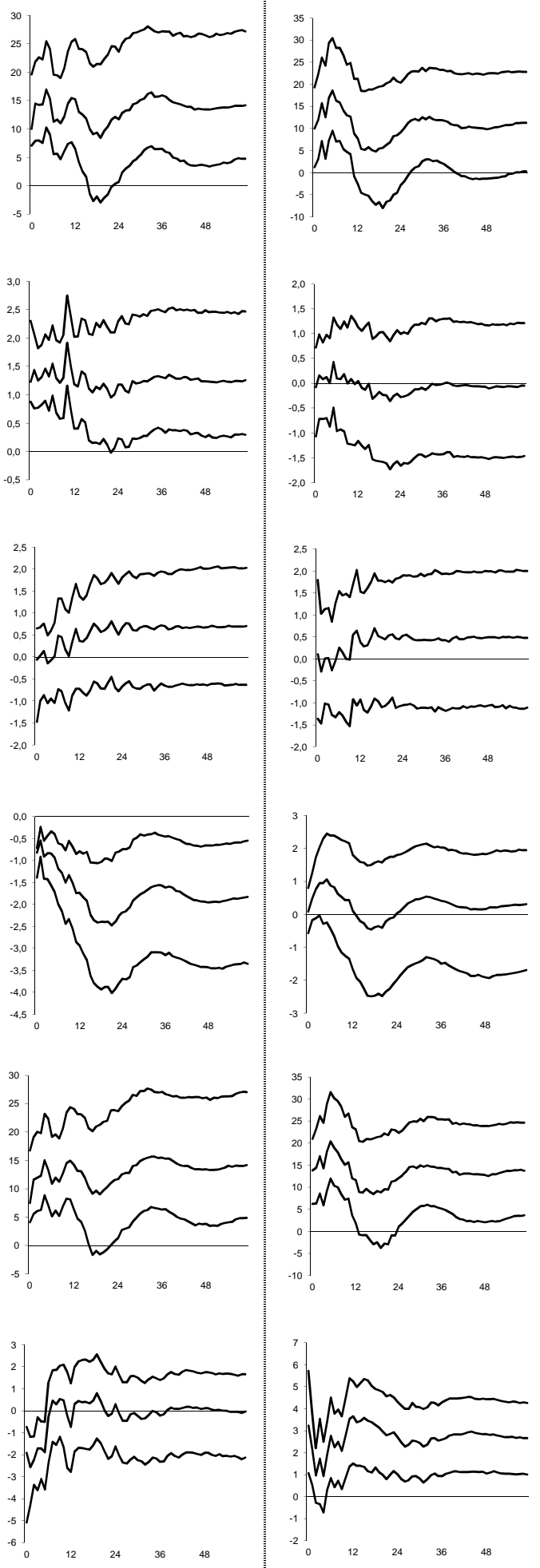

\section{Figure 1 - Impulse response functions following different types of oil shocks}

Notes: $68 \%$ probability range together with the median response of the posterior distribution, responses are in percentages and shown in levels up to 60 months after the shock. The oil shocks are normalised to increase oil prices with $10 \%$ on impact. 
Oil spot price

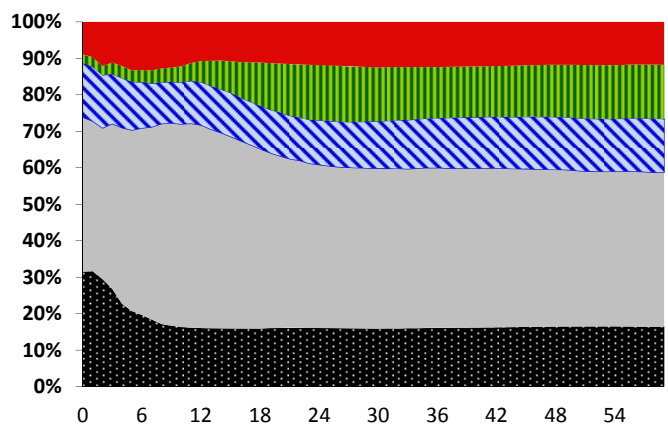

D oil supply

oil demand driven by econ. activity

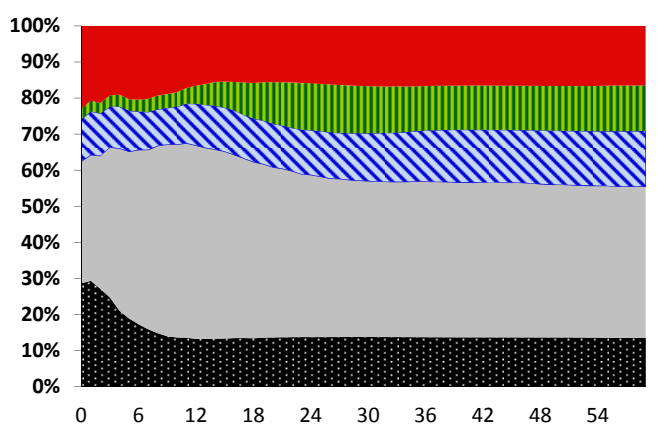

D oil-specific demand

III other

destab. fin. activity

Figure 2 - Forecast error variance decomposition

Notes: Forecast error decomposition in percentages based on the posterior median draw. 


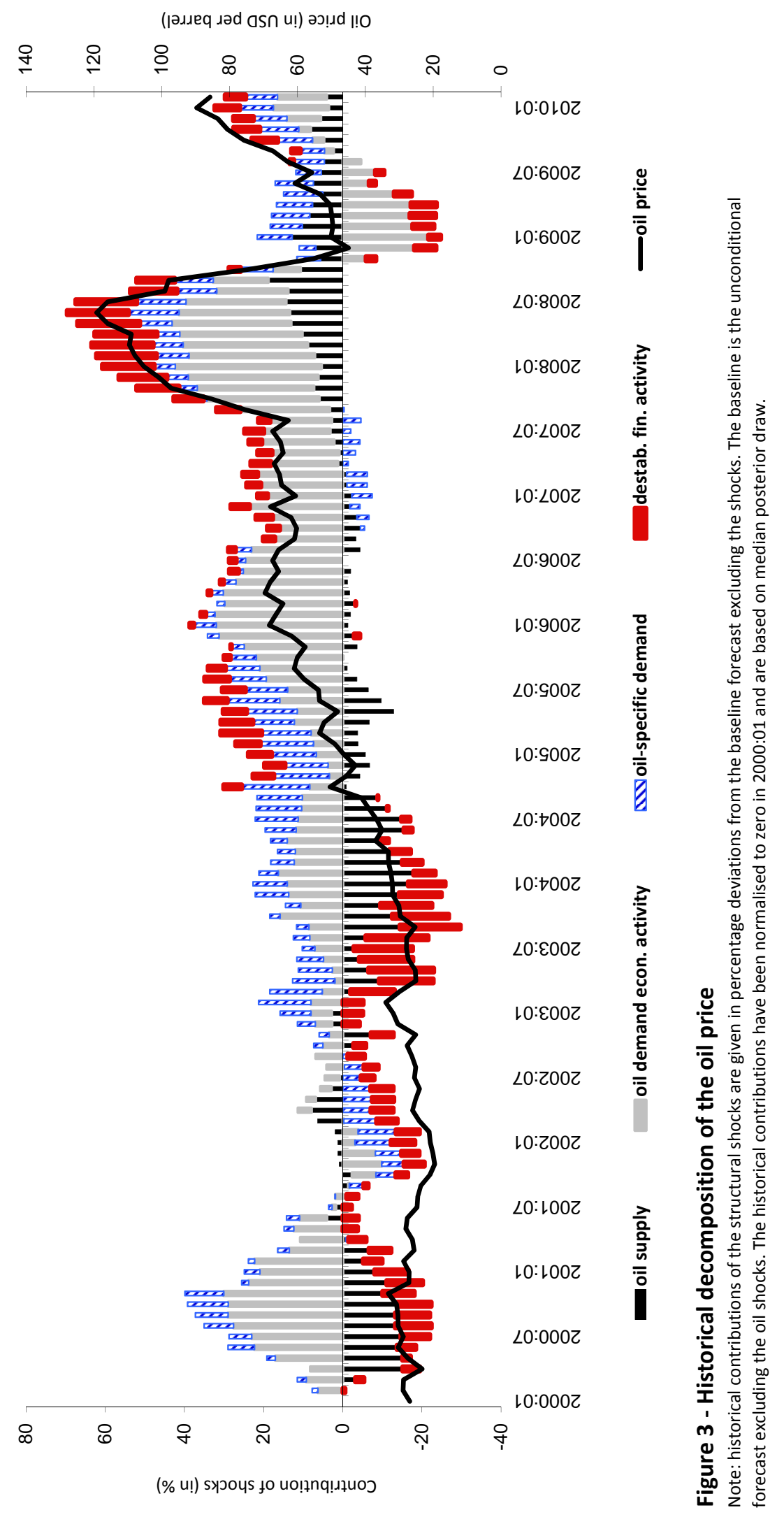


Figure 4 - Robustness of the forecast error variance decomposition

Oil spot price

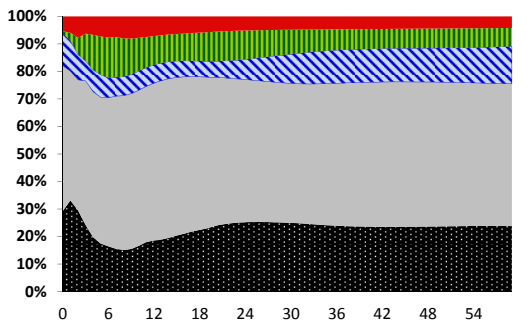

B oil supply oil demand driven by econ. activity
Oil futures price

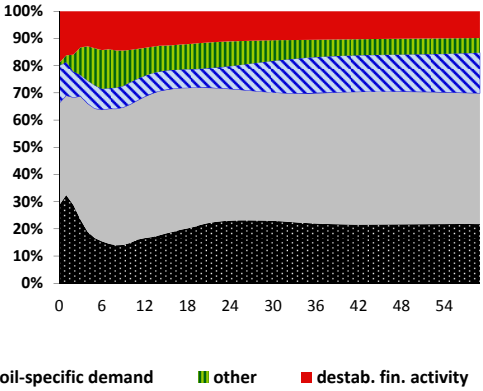

Panel A - Forecast error variance decomposition based on the 'Fry and Pagan' draw

Notes: Forecast error decomposition in percentages based on the posterior draw that minimizes the distance with respect to the median of the posterior of all the responses.

Oil spot price

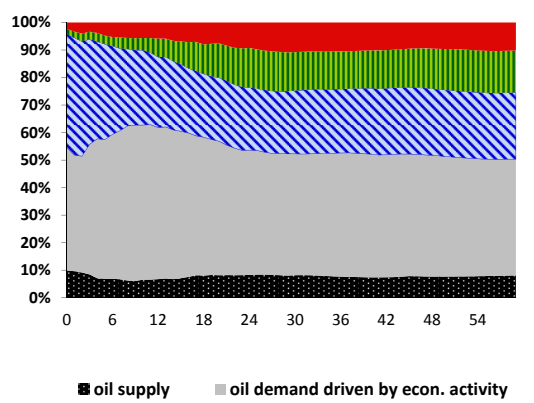

Oil futures price

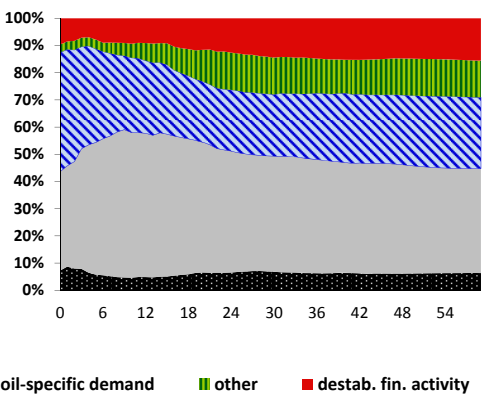

Panel B - Forecast error variance decomposition based on the 'Kilian and Murphy' draw

Notes: Forecast error decomposition in percentages based on the posterior median draw generated by the SVAR model with additional restrictions on the price elasticity of oil supply and demand. 


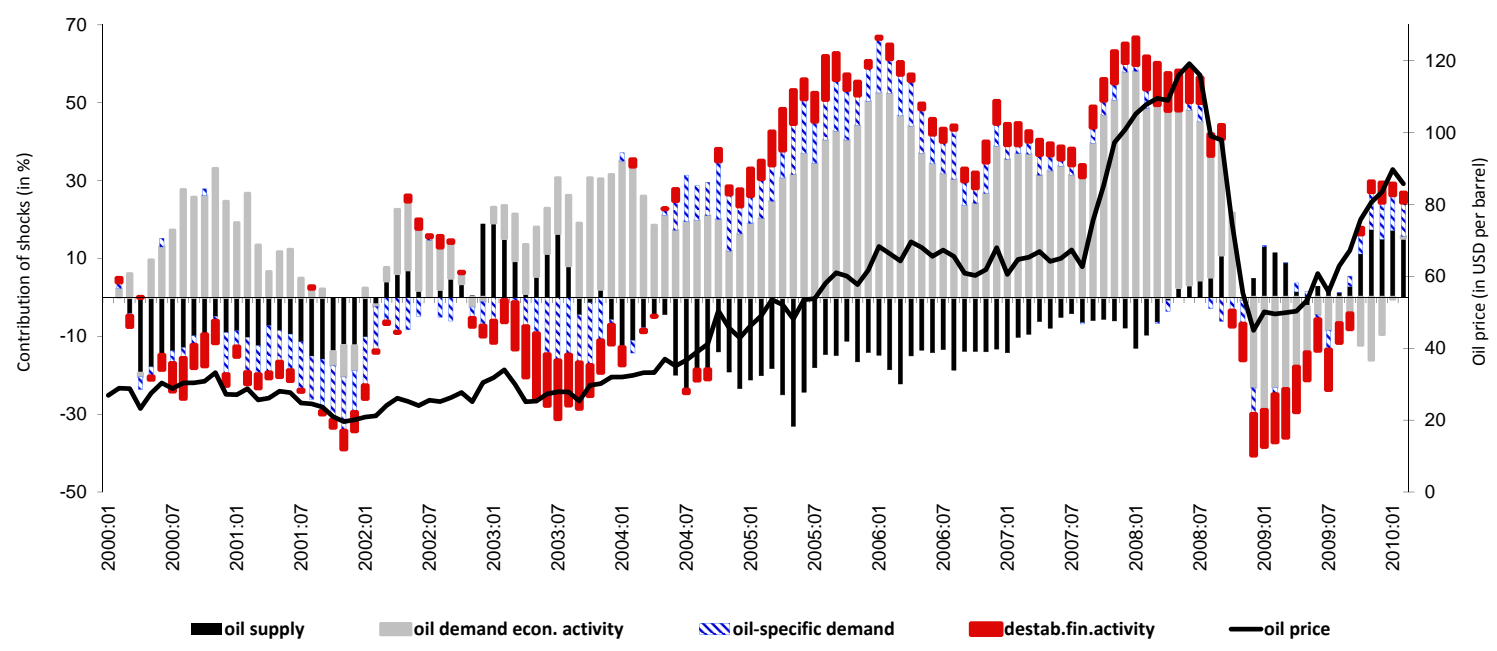

Panel A - Historical decomposition of the oil price based on the 'closest-to-median' draw

Note: historical contributions of the structural shocks are given in percentage deviations from the baseline forecast excluding the shocks. The baseline is the unconditional forecast excluding the oil shocks. The historical contributions have been normalised to zero in 2001:01 and are based on the posterior draw that minimised the distance to the median from the posterior of all the responses.

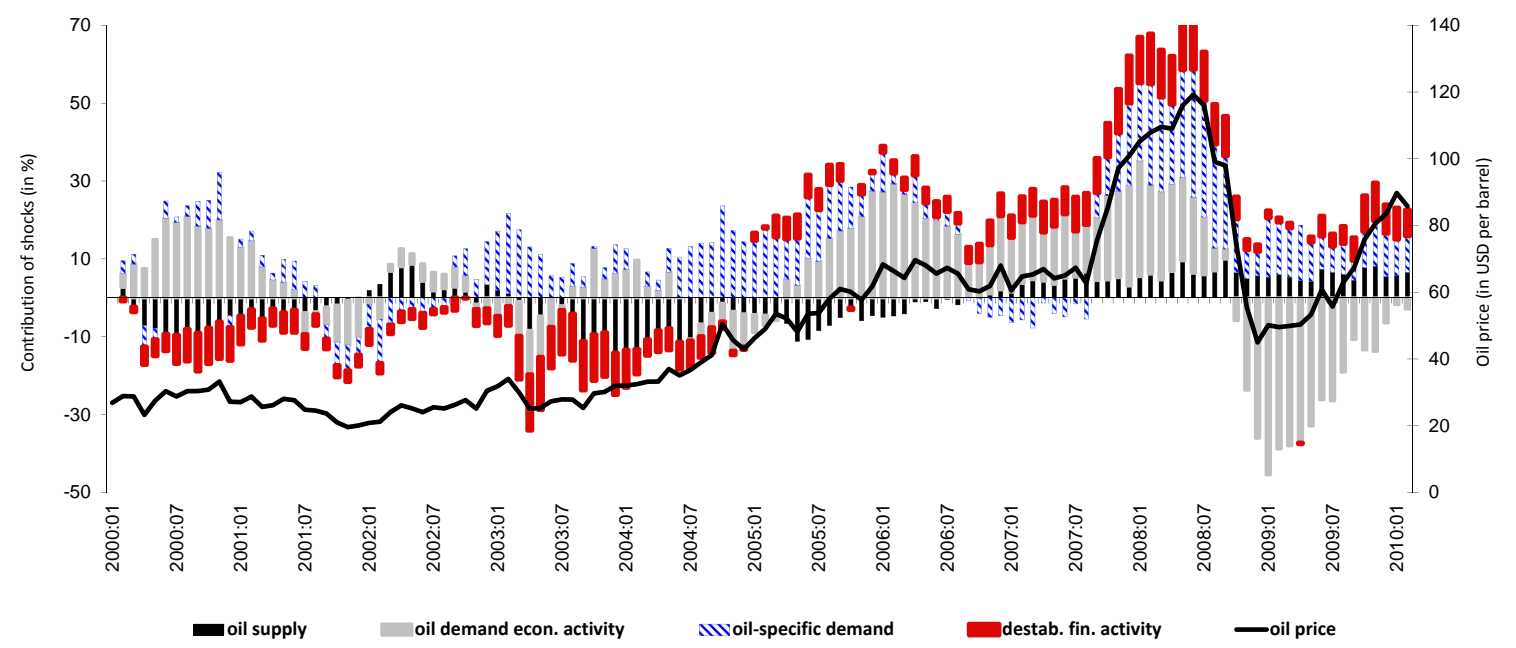

Panel B - Historical decomposition of the oil price based on the 'Kilian and Murphy' draw

Note: historical contributions of the structural shocks are given in percentage deviations from the baseline forecast excluding the shocks. The baseline is the unconditional forecast excluding the oil shocks. The historical contributions have been normalised to zero in 2000:01 and are based on the median posterior draw generated by the SVAR model with additional restrictions on the price elasticity of oil supply and demand. 
